УДК 686.1.056.22:621.91:655.28

\title{
ДОСЛІДЖЕННЯ ВПЛИВУ ГЕОМЕТРИЧНИХ ПАРАМЕТРІВ НОЖА НА ЗУСИЛЛЯ РОЗРІЗУВАННЯ СТОПИ НА ПАПЕРОРІЗАЛЬНІЙ МАШИНІ
}

(๖ Ю. П. Мамонов, к.т.н., доцент, В. В. Білоус, НТУУ «КПІ", Київ, Україна

\section{В статье рассматривается влияние одного из параметров - угла начального наклона ножа, на усилия, которые возникают в процессе резания стопы.
In article influence of one of parameters - a corner of an initial inclination of a knife, on efforts which stops arise during cutting is examined.}

\section{Постановка проблеми}

Як відомо зусилля опору врізання ножа визначається трьома складовими: вертикальною $\mathrm{P}_{\mathrm{z}}$, лобовою $\mathrm{P}_{\mathrm{y}}$ і горизонтальною $\mathrm{P}_{\mathrm{x}}$. На ці складові впливають різноманітні фактори, що виникають в процесі розрізування стопи.

Найбільшими складовими $€$ вертикальна сила $\mathrm{P}_{\mathrm{z}}$ і горизонтальна сила $\mathrm{P}_{\mathrm{x}}$. Типовим залишається також характер їх зміни від початку врізування ножа в стопу до її повного розрізування [1].

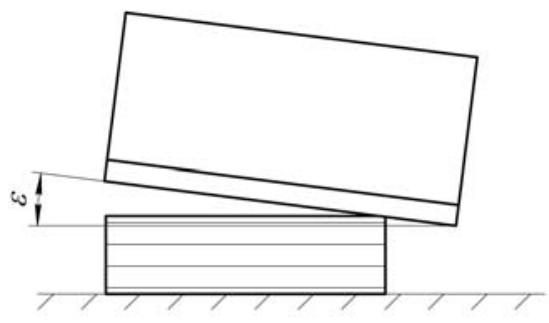

a
При шабельній траєкторії руху ножа розташування ножа відносно стопи має два характерних положення: на початку врізування ножа, коли він знаходиться відносно стопи під кутом $\varepsilon$, в кінці розрізування, при виході ножа зі стопи, коли ріжуча кромка ножа займає положення паралельне відносно стола машини (рис. 1).

\section{Аналіз попередніх досліджень}

Експериментальні дослідження процесу розрізування стопи

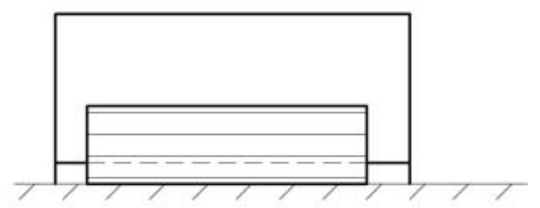

б

Рис. 1. Характерні етапи розрізування стопи: а - початок взаємодії ножа зі стопою; б - кінцеве розташування ножа при виході зі стопи 
паперу клиновидним ножем проводили в своїх роботах Гінзбург В. 3. [2], Георгієвський І. К. та інші [3]. Георгієвський в своїй роботі розробив трьохкомпонентну систему вимірювання сил різання в паперорізальних машинах.

В. 3. Гінзбург в своїй роботі по дослідженню процесу різання на одноножових паперорізальних машинах [3] провів ряд досліджень, які дозволили отримати потрібні дані для подальшого дослідження процесу рі- зання. Узагальнення результатів експериментальних даних дозволили автору вивести емпіричні формули для основних складових сил різання, горизонтальної і вертикальної, для характерних етапів: на початку входження ножа в стопу і в кінці розрізування стопи.

Аналіз літературних джерел, результатів теоретичних та експериментальних досліджень свідчать, що авторами не розглядались питання впливу кута початкового нахилу ножа $\varepsilon$ на зусилля

Таблиця 1

Параметри машини (технічні характеристики), матеріалу, режимів роботи та умов експлуатації

\begin{tabular}{|c|c|c|c|}
\hline Назва параметру & Позначення & $\begin{array}{c}\text { Одиниці } \\
\text { вимірювання }\end{array}$ & Діапазон значень \\
\hline Довжина стопи & $\mathrm{L}$ & MM & $76-155$ \\
\hline Висота стопи & $\mathrm{H}$ & Mм & $110-165$ \\
\hline Тиск притиску & Q & $\mathrm{H}$ & $4000-55000$ \\
\hline Питомий тиск притиску & q & $\mathrm{H} / \mathrm{MM}$ & - \\
\hline Кут заточки ножа & $\alpha$ & град & $19-24$ \\
\hline Кут траєкторії руху ножа & $\theta$ & град & $40-45$ \\
\hline $\begin{array}{l}\text { Число обертів головного вала } \\
\text { машини }\end{array}$ & $\mathrm{n}$ & об./хв. & $40-50$ \\
\hline $\begin{array}{l}\text { Початковий кут врізання ножа } \\
\text { в стопу }\end{array}$ & $\varepsilon$ & град & $1-3$ \\
\hline Відносна вологість паперу & $\mathrm{B}$ & $\%$ & - \\
\hline $\begin{array}{l}\text { Коефіцієнт гостроти заточки но- } \\
\text { жа }\end{array}$ & $\mathrm{K}_{\mathrm{O}}$ & - & $0,556-3,054$ \\
\hline $\begin{array}{l}\text { Коефіцієнт кута траєкторії руху } \\
\text { ножа }\end{array}$ & $\mathrm{K}_{\theta}$ & - & $0-1,045$ \\
\hline Коефіцієнт швидкості руху ножа & $\mathrm{K}_{\mathrm{n}}$ & - & $0,562-1,453$ \\
\hline $\begin{array}{l}\text { Коефіцієнт, що враховує фізико- } \\
\text { механічні властивості паперу }\end{array}$ & $\mathrm{K}_{\mathrm{m}}$ & 一 & $0,29-1,68$ \\
\hline Коефіцієнт змащення леза ножа & $\mathrm{K}_{\mathrm{C}}$ & - & $0,79-1$ \\
\hline
\end{tabular}




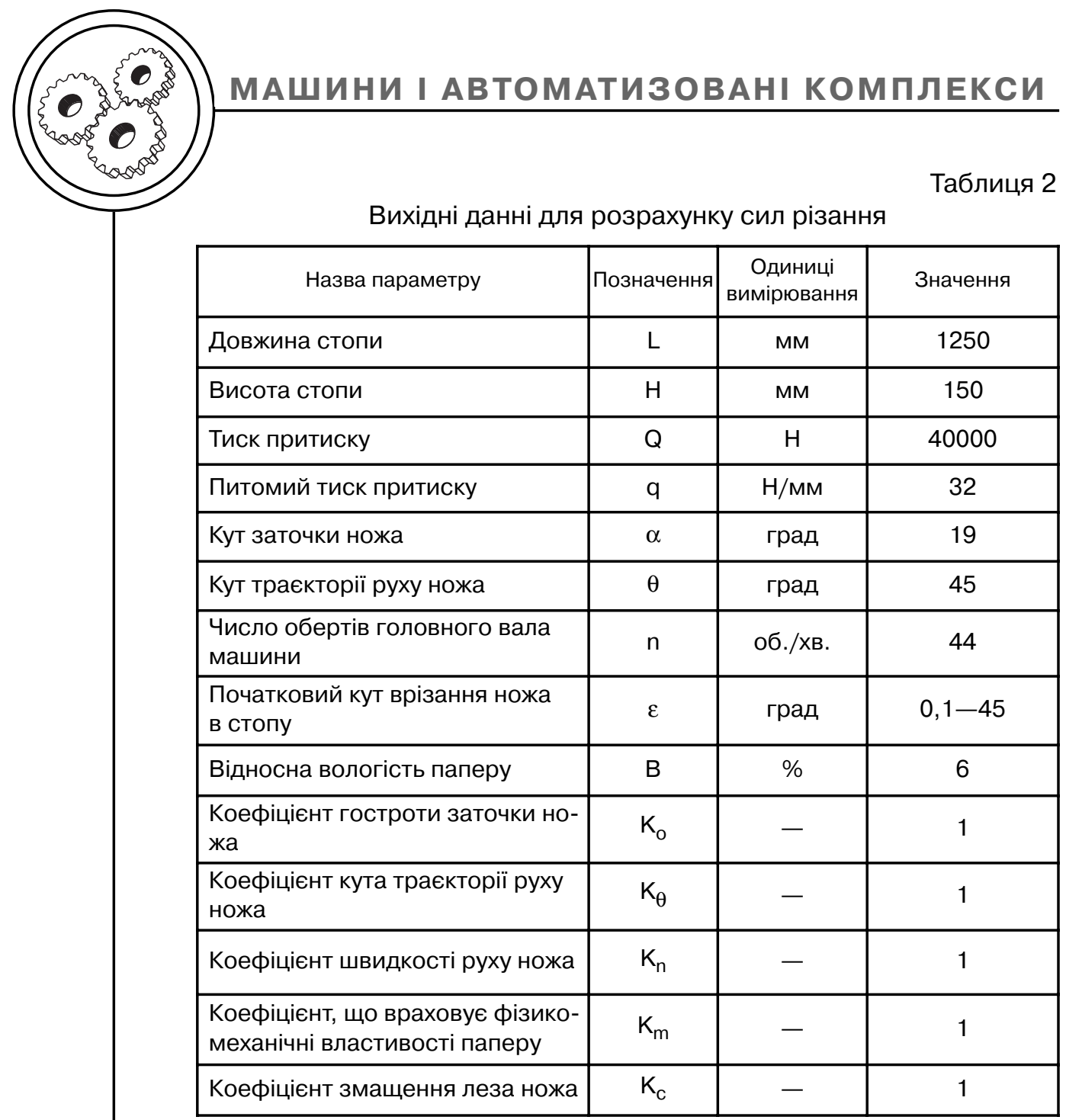

розрізування стопи при шабельному русі ножа.

\section{Мета роботи}

На базі існуючих теоретичних залежностей проводиться комплексне теоретичне дослідження впливу кута початкової установки ножа $\varepsilon$ на зусилля, що виникають при розрізуванні паперових матеріалів. Причому, досліджується зусилля для двох характерних етапів розрізування: на початку врізування ножа в стопу і при виході ножа зі стопи.

\section{Результати проведених досліджень}

Для визначення складових сил різання скористаємось емпіричними формулами які наводяться в роботах [2, 3], які з урахуванням характерних етапів руху ножа дозволяють визначити складові сил різання:

1. На початку взаємодії ножа зі стопою (врізування) (рис. 1, a):

а) горизонтальна складова на початку розрізування визначається за формулою: 


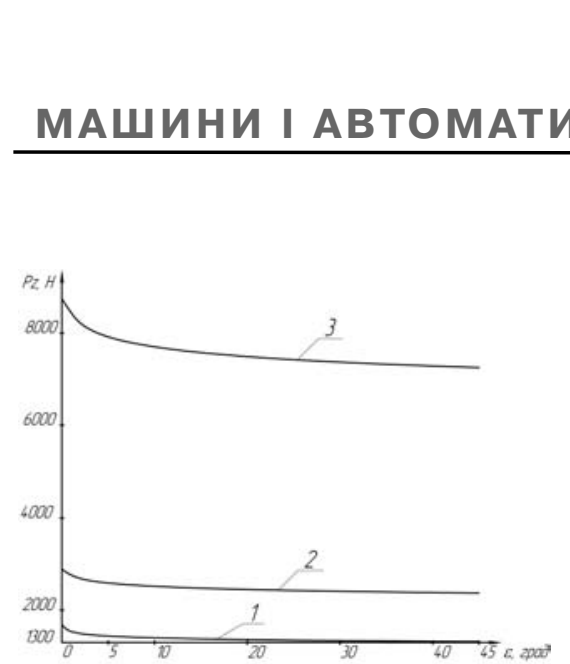

a

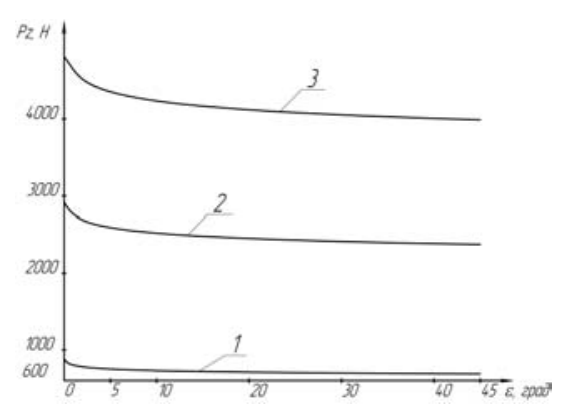

B

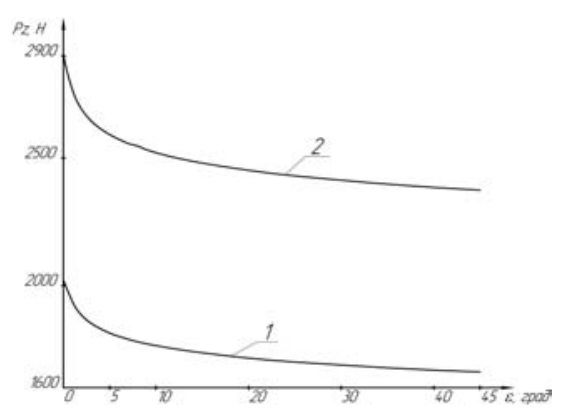

Д

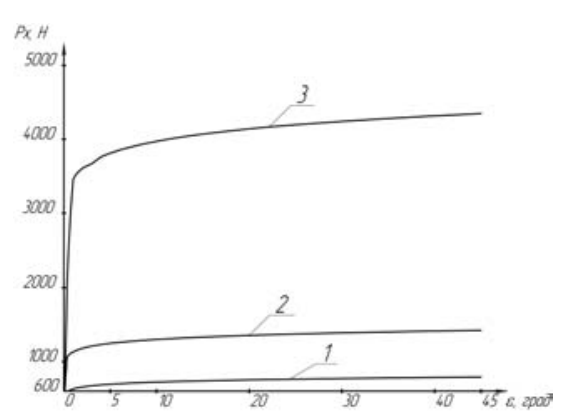

б

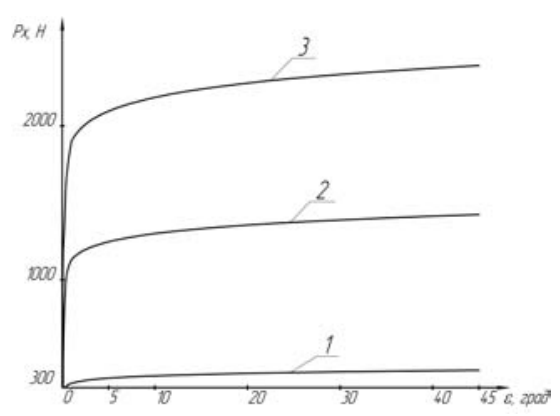

$\Gamma$

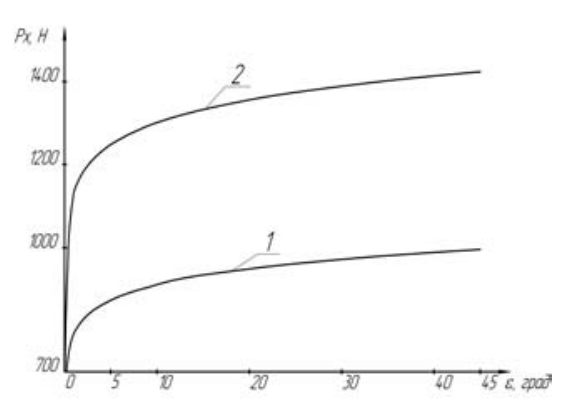

e

Рис. 2. Графіки залежності вертикальної $\mathrm{P}_{\mathrm{z}}$ та горизонтальної $\mathrm{P}_{\mathrm{x}}$ складових сил різання в залежності від кута нахилу ножа є: а, б - коефіцієнт, що враховує гостроту ножа 1) 0,556; 2) 1; 3) 3,054; в, г-коефіцієнт, що враховує фізико-механічні властивості матеріалу 1) 0,29; 2) 1; 3) 1,68; д, е коефіцієнт, що враховує змащення ножа 1) 0,7; 2) 1 


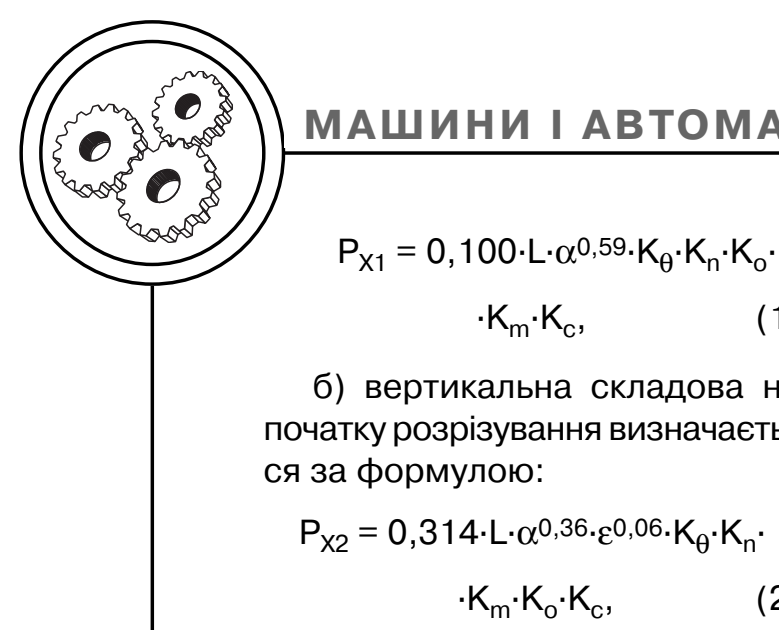

2. В кінці взаємодії ножа зі стопою (рис. 2, б):

а) горизонтальна складова в кінці розрізування визначається за формулою:

$$
\begin{aligned}
& \mathrm{P}_{\mathrm{Z} 1}=\frac{0,423 \cdot \mathrm{L} \cdot \alpha^{0,32} \cdot \theta^{0,33} \cdot \mathrm{q}^{0,1}}{\mathrm{H}^{0,09} \cdot \mathrm{n}^{0,05} \cdot \varepsilon^{0,04} \cdot \mathrm{B}^{0,14}} \cdot \\
& \cdot \mathrm{K}_{\mathrm{o}} \cdot \mathrm{K}_{\mathrm{m}} \cdot \mathrm{K}_{\mathrm{c}}
\end{aligned}
$$

б) вертикальна складова в кінці розрізування визначається за формулою:

$$
\begin{aligned}
& \mathrm{P}_{\mathrm{Z} 2}=\frac{0,100 \cdot \mathrm{L} \cdot \alpha^{0,24} \cdot \theta^{0,76}}{\mathrm{n}^{0,07} \cdot \mathrm{B}^{0,08}} \cdot \\
& \cdot \mathrm{K}_{\mathrm{o}} \cdot \mathrm{K}_{\mathrm{m}} \cdot \mathrm{K}_{\mathrm{c}} \cdot
\end{aligned}
$$

у формулах враховані такі основні параметри які впливають на сили, що виникають при розрізуванні стопи плоским клиноподібним ножем: довжина стопи - L, висота стопи - H, кут заточки ножа $-\alpha$, зусилля приписку стопи - q, кут траєкторії ножа $-\theta$, число обертів головного вала машини - n, початковий кут нахилу ножа $-\varepsilon$, відносна вологість паперу - В та коефіцієнти, що враховують гостроту заточки ножа $-\mathrm{K}_{\mathrm{o}}$, кут траєкторії руху ножа $-\mathrm{K}_{\theta}$, швидкість руху ножа $-\mathrm{K}_{\mathrm{n}}$, фізико-механічні властивості розрізаємого матеріалу $-\mathrm{K}_{\mathrm{m}}$, змащення леза ножа $-\mathrm{K}_{\mathrm{c}}$. Усі параметрі зведено в таблицю 1.

Для чисельних розрахунків сил були використані параметри які можуть практично реалізовуватися в сучасних моделях різальних машин. В таблиці (табл. 2) наводяться вихідні данні, відповідно до технічних характеристиках широкоформатної різальної машини БР-125 [4].

На підставі формул (1-4) i вихідних даних (табл. 1, 2) були проведені комп'ютерні розрахунки із застосуванням програмного продукту MathCad 11a. На базі отриманих даних були побудовані графіки сил різання в залежності від параметрів (рис. 2).

Аналіз графіків свідчить про залежність складових сил різання від кута початкового встановлення ножа $\varepsilon$. Причому, при збільшенні кута вертикальна складова зменшується, а горизонтальна навпаки збільшується. При цьому найбільш інтенсивні зміни складових сил різання відбуваються при значенні кута в межах $0,1^{\circ}-5^{\circ}$. Також 3 графіків помітно, що вплив кута тим більше чим більше затуплений ніж (рис. 2, а, б), більшої щільності матеріал (рис. 2, в, г) i відсутнє спеціальне змащення (рис. 2, д, е).

\section{Висновки}

Літературний огляд робіт дозволив визначитися щодо існуючих досліджень впливу параметрів на зусилля різання. Вибрано математичний апарат для теоретичного розрахунку залежностей зусиль різання роз- 
роблений на базі емпіричних формул. Розроблена програма теоретичних досліджень. Виконані числові розрахунки та побудовані графіки. Отримані залежності геометричних параметрів руху ножа на зусилля розрізування.
На підставі вище зазначених висновків можна рекомендувати в механізмі ножа використання меншого значення кута початкової установки. Отримані результати можуть бути використані при проектуванні нового та модернізації існуючого обладнання.

1. Пергамент Д. А. Брошюровочно-переплетное оборудование. - М.: МПИ, 1990. - 452 с. 2. Гинзбург В. 3. Исследование процесса резания на одноножевых резальных машинах // Сб. трудов ВНИИПМ. - 1957. - № 3. 3. Георгиевский И. К., Полюдов А. Н., Иващенко В. Т. Измерение усилий резания в бумагорезальных машинах // Полиграфия. - 1977. - № 1. - С. 30-31. 4. Хведчин Ю. Й. Брошурувально-палітурне устаткування. Ч. 1. Львів: ТеРус, 1999. -336 с.

\section{Рецензент - І. Т. Гетьман, к.т.н.,} доцент, НТУУ «КП|»

Надійшла до редакції 14.05.08 